\title{
Análise do comportamento socioambiental terena por meio de marcadores espaço-temporais: uma contribuição para a conservação da cultura
}

\author{
Analysis of behavior in environmental terena by space-temporary markers: a \\ contribution to the conservation of culture

\section{Analyse du comportement en environnement terena marqueurs espace media-temporaire: une contribution à la conservation de la culture}

\author{
Análisis del comportamiento en el medio ambiente terena marcadores media-espacio \\ temporal: una contribución a la conservación de la cultura \\ Sandra Ventura Domingo* \\ Elisangela Castedo Maria* \\ Recebido em 15/08/2016; revisado e aprovado em 16/08/2016; aceito em 16/08/2016 \\ DOI: http:/ / dx.doi.org/10.20435/1984-042X-2016-v.18-n.1(05)
}

\begin{abstract}
Resumo: A cultura Terena tem sido reconstruída, ao passado são adicionadas ideias novas, o que é uma tática de resistência (PEREIRA, 2009) mesclando velhos hábitos a hábitos novos acompanhando a evolução. Plantio, coleta e caça realizados, com conhecimento tradicional, são regidos pelos marcadores espaço-temporais e associados às técnicas modernas de agricultura por uma parcela pequena da população. O objetivo desta pesquisa foi levantar o comportamento socioambiental Terena e a cultura tradicional inserida ali.
\end{abstract}

Palavras-chave: etnia Terena; cultura, marcadores espaço-temporais.

Abstract: The Terena culture has been rebuilt in the past are added new ideas, which is a tactic of resistance (PEREIRA, 2009) merging old habits to new habits in line with developments. Planting, gathering and hunting, performed with traditional knowledge, are governed by the spatio-temporal markers, and associated with modern farming techniques for a small portion of the population. The objective of this research was to raise the Terena environmental behavior and traditional culture inserted there.

Key words: Terena ethnicity; culture; bookmarks space-time.

Résumé: La culture Terena a été reconstruit dans le passé sont ajoutés de nouvelles idées, ce qui est une tactique de résistance (PEREIRA, 2009) fusionner les vieilles habitudes à de nouvelles habitudes en ligne avec l'évolution. La plantation, cueillette et de chasse, réalisée avec les connaissances traditionnelles, sont régies par les marqueurs spatio-temporelles, et associés à des techniques agricoles modernes pour une petite partie de la population. L'objectif de cette recherche était d'élever le comportement environnemental Terena et la culture traditionnelle il inséré.

Mots-clés: Terena blanche; culture; marque l'espace-temps.

Resumen: La cultura Terena ha sido reconstruido en el pasado se añaden nuevas ideas, que es una táctica de la resistencia (PEREIRA, 2009) la fusión de viejos hábitos a los nuevos hábitos en consonancia con la evolución. La siembra, la recolección y la caza, realizado con los conocimientos tradicionales, se rigen por los marcadores de espacio-temporales, y se asocian con las técnicas modernas de cultivo para una pequeña parte de la población. El objetivo de esta investigación fue elevar el comportamiento medioambiental Terena y la cultura tradicional insertado allí.

Palabras clave: Terena etnia; cultura, marcadores espacio-tiempo.

\section{INTRODUÇÃO}

Os povos indígenas no Brasil organizam-se em vários grupos diferentes entre si, constituindo, junto com outros povos descendentes de imigrantes italianos, árabes, espanhóis, alemães, dentre outros, a nação brasileira. Historiadores contam que a ocupação do território americano pelos grupos indígenas é anterior à

\footnotetext{
* Universidade Federal do Mato Grosso do Sul, Campo Grande, Mato Grosso do Sul, Brasil.
} 
chegada dos europeus no continente, por migrações de populações indígenas diferentes, que estabeleceram contato entre si e trocavam experiências, e faziam alianças que diversificavam heranças culturais ou por meio de guerras, no intuito de dominar áreas mais férteis ou de fácil comunicação (BITTENCOURT; LADEIRA, 2000).

A população indígena do Brasil é constituída por diversos povos diferentes, cada um com hábitos, costumes e crenças característicos. $\mathrm{O}$ direito à diferença cultural está assegurado na Constituição Brasileira de 1988, no Artigo 231 que diz que "são reconhecidos aos índios sua organização social, costumes, línguas, crenças e tradições, e os direitos originários sobre terras que tradicionalmente ocupam, competindo à União demarcá-las, proteger e fazer respeitar todos os seus bens".

Nas perspectivas da Constituição Federal (CF), os povos indígenas têm direito de se organizar de forma própria, pois constituem vários grupos diferentes, com línguas diferentes, crenças diferentes, costumes, hábitos diferentes, sendo responsabilidade da União assegurar os direitos dos povos indígenas e zelar pela sua cidadania.

Os Terena ocupam várias regiões do Brasil, podendo ser identificados por meio de pontos marcantes de sua cultura, tais como o artesanato, tecelagem, instrumentos musicais e a agricultura, praticada a partir dos saberes tradicionais, advindos de observações feitas sobre a natureza, marcadores espaço-temporais, foco principal deste trabalho.

Ao longo do seu contato com o não indígena, os Terena têm estabelecido uma relação de verticalidade, da qual as consequências têm impactado seus hábitos, costumes, culturas, tradições e mobilidade social, hoje não se movimentam pelos seus territórios originais, coletando, plantando e caçando, pois estes se encontram ocupados por proprietários que compraram os títulos das Terras Indígenas vendidas pelo próprio Governo no passado. Para melhor entender o momento em que o Terena vive hoje, é necessário fazer uma releitura da sua história.

Nesse sentido, este trabalho tem por objeto caracterizar e registrar os marcadores espaço-temporais Terena para que os conhecimentos atuais e saberes antigos, anteriormente aprendidos, durante gerações, exclusivamente de forma oral, não se percam com o tempo em função da mudança de hábitos e costumes dos jovens Terena. Para tanto, fez-se necessário um levantamento bibliográfico e uma pesquisa de campo por meio de entrevistas para conhecer e registrar:

1. os marcadores espaço-temporais Terena

2. hábitos e costumes;

3. destacar a relação dos Terena com o ambiente;

4. contribuir para conservação cultural para que os conhecimentos atuais e saberes antigos, anteriormente aprendidos, durante gerações, exclusivamente de forma oral, não se percam com o tempo em função da mudança de hábitos e costumes dos jovens Terena.

Essa verificação se faz fundamental para entender a vida que os Terena levam na atualidade.

\section{OBSERVAÇÕES DO HOMEM A PARTIR DA NATUREZA}

O homem é classificado de acordo com a taxonomia como sendo do Reino Animal, Filo Chordata, Classe Mammalia, Ordem Primata, Família Hominidae, Gênero Homo e Espécie Homo Sapiens. O corpo humano é uma máquina formada por trilhões de células, unidade básica da vida, essas células formam o tecido, os tecidos formam os órgãos, os órgãos formam os sistemas e estes constituem a máquina do corpo humano, que carregam informações genéticas que controlam todas as atividades do ser humano (MORIN, 1973). 
O que diferencia o homem dos outros animais é o fato de ser dotado de inteligência e ser social. O homem aprimorou sua forma de comunicação, assim como sua forma de subsistência, quando passou de coletor nômade a agricultor. No decorrer de sua evolução, de forma empírica, o homem passou a dominar as técnicas de manejo de solo e culturas. Tal conhecimento foi se acumulando e sendo repassado no decorrer das gerações, e isso é chamado de cultura.

Segundo Thomaz (1995, p. 427-428), entende-se cultura:

[...] como um código simbólico - código que possui uma dinâmica e uma coerência interna, é compartilhado pelos membros de uma sociedade ou grupo social, e que, mediante um procedimento antropológico, pode ser decifrado e traduzido para membros que não pertencem a este grupo [...] este código simbólico não é dado [...] não recebemos como uma herança biológica as formas do nosso comportamento ou os significados que atribuímos às nossas ações ou ao mundo que nos rodeia. A cultura se refere pois à capacidade - e necessidade - que os seres humanos têm de aprender.

cultura é:

Para Tassinari (1995, p. 448-449)

O conjunto de símbolos partilhado pelos integrantes de determinado grupo social e que lhes permite atribuir sentido ao mundo em que vivem e às suas ações. [...] O código simbólico que chamamos de "cultura" permeia todos os momentos da vida social. [...] a cultura diz respeito a uma capacidade comum a toda a humanidade. Esta é a condição básica para a possibilidade do "diálogo cultural", ou seja, mesmo que eu viva e entenda o mundo a partir de um conjunto de significados próprios, posso compreender modos diferentes de viver e dar sentido ao mundo. [...] cultura é compartilhada, formulada e transformada por um determinado grupo social. [...] toda cultura é dinâmica, ou seja, vai se transformando através da história.

Nesse sentido, cultura é a relação da espécie humana com o mundo em que vive, está relacionada à aprendizagem das manifestações artísticas, sociais, linguísticas e comportamentais de um povo como: música, teatro, rituais religiosos, língua falada e escrita, mitos, hábitos alimentares, danças, arquitetura, invenções, pensamentos, formas de organização social, formas de dar sentido ao mundo etc. (MARIA, 2011).

É evidente que, ao interagir com o meio ou "mundo", a espécie humana o transforma e que essa transformação se dá de diferentes formas porque isso também depende da cultura e percepções de cada grupo, sendo assim muito subjetivo.

Dessa forma, o ser humano dominou a natureza subjugando-a segundo suas ambições. O domínio da natureza se deu ao longo de sua vida na Terra, por meio de suas percepções, observações e experimentos.

\section{COMPORTAMENTO HUMANO AO OBSERVAR A NATUREZA}

Não é necessário ser antropólogo, paleontólogo, biólogo, geógrafo, ou qualquer outra profissão ligada ao meio ambiente para observar que à nossa volta, marcas residentes do passado vêm preencher memórias socioambientais, tanto na mitologia, rituais ou ciclos ambientais.

Observando a natureza, os movimentos celestiais e os processos físico-biológicos a sociedade incansavelmente age e se transforma, sistematizando seus anseios e aspirações em técnicas e trabalho. Muitas invenções do ser humano foram realizadas por meio de observações 
da natureza, como por exemplo, a criação da luz artificial a partir das naturais, os aviões a partir dos pássaros, o velcro a partir da observação da semente de Arctium que grudava nas roupas e em pelos de animais, entre outras.

Este estudo dos hábitos e comportamento dos animais (fora dos laboratórios) é chamado de etologia e revolucionou tudo o que se julgava conhecer sobre o mundo dos animais. Entretanto, como todo começo, nada foi fácil, os primeiros estudiosos observavam solitariamente o comportamento dos animais. Julgavase que os animais se comportavam de modo automático e por reflexos, ou seja, acreditava-se que seus comportamentos eram meras reações influenciadas ou regidas pelo meio, quer por reflexos, quer por instintos, na tentativa de garantir a sua sobrevivência e a sua reprodução, ou seja, perpetuação da espécie (MORIN, 1973).

A etologia veio assegurar que o comportamento animal é sistematicamente organizado e organizador. Primordialmente, surgem as noções de comunicação e territoriedade. Os animais se comunicam, emitem mensagens e estas são interpretadas por uma espécie específica (MORIN, 1973).

Essas mensagens não são apenas sonoras, uma vez que podem ser visuais ou olfativas. No passado, acreditava-se que a comunicação entre os animais fosse uma coisa comum, de caráter exclusivamente, ou voltada apenas para a relação sexual. A etologia veio para desmistificar essa verdade absoluta, os sons, gestos, não se referem apenas ao ato de acasalamento, mas de cooperação, advertência, ameaça, submissão, amizade e brincadeiras. E o que acontece de mais extraordinário, às vezes, essa comunicação é simbólica, ou seja, um determinado comportamento, com um significado específico, é transportado para fora da situação, no intuito de exprimir uma mensagem simbólica, é como se os animais usassem as nossas figuras de linguagem.
[...] a brincadeira animal pressupõe uma comunicação sobre a natureza da comunicação (metacomunicação): mordiscar parece-se com morder, mas significa o contrário, brincar, isto é, amizade, e não conflito; o pseudoconflito lúdico transforma-se em expressão de entendimento. Verifica-se assim que, naquilo que parecia tão evidente e tão simples, a brincadeira, emerge a complexidade comunicacional, a qual se pode desenvolver de outra maneira no estratagema, no disfarce, na camuflagem. (MORIN, 1973, p. 12).

Sendo assim, pode-se dizer que a comunicação entre os animais abrange um patamar muito mais complexo do que se imaginava, muito além da relação sexual, na verdade, trata-se de uma variedade de relações interindividuais, dentre as quais se destacam a amizade, a proteção, a submissão, a intimidação, dentre outras. Trata-se também de outra questão bastante relevante para este trabalho, os fenômenos organizacionais básicos, tais como a regulação demográfica e a territoriedade (MORIN, 1973).

A etologia descobriu que a noção de território para os animais, está aquém das atividades de um indivíduo, espécie, trata-se, também da relação com o outro, ou seja, está ligada às outras espécies, outros hábitos, outros nichos. Mesmo um galinheiro, uma alcateia ou uma colmeia, à primeira vista nos parece uma desordem total, sem sincronia, todavia, ao serem observados adequadamente, nota-se que todo movimento obedece a uma hierarquia, que, na realidade, é muito rígida e organizada (MORIN, 1973).

\section{SOCIOLOGIA ANIMAL}

A sociologia humana julgava-se única no mundo humano, todavia acreditava-se que tanto as sociedades das formigas, quanto das abelhas, na realidade, não passavam de instintos cegos. A biologia 
interpretava essas sociedades como sendo casos únicos, quando na verdade se tratava de comportamentos específicos da espécie, e não o desenvolvimento particular da sociologia animal.

Tal sociedade organiza e protege, logicamente, o seu território, estruturando-se hierarquicamente, ainda que esta resulte de conflitos e disputas, que implicam em relações interindividuais. Essas relações implicam no quão grande é a riqueza da comunicação entre os animais, culminando na complexidade e diversidade destas. A diversidade dos símbolos de comunicação vai variar de espécie a espécie, de indivíduo a indivíduo, delineando e aumentando essa complexidade, portanto a etologia fundamenta a sociologia animal.

A etologia tem fomentado e embasado estudos referentes ao comportamento animal, e esses estudos é que fundamentam a teoria de que a sociedade é amplamente espalhada e assume formas diferentes em função de fatores diversos, porém toda sociedade é uma auto-organização dos sistemas vivos. É nesse contexto que se insere a sociedade humana, que surge como uma variante de desenvolvimento do fenômeno social natural. Ou seja, a organização em sociedade não é um fenômeno meramente humano, mas a sociedade humana é que se insere como uma variante das diversas sociedades do mundo animal.

Deste modo, as consequências da etologia e da sociologia animal são igualmente mortais para o paradigma fechado do antropologismo. Chega-se à conclusão de que nem a comunicação, nem o símbolo, nem o rito, são exclusividades humanas, e de que têm raízes muito remotas na evolução das espécies. (MORIN, 1973, p. 14).

Sendo assim, pode-se afirmar que não foi o ser humano o pioneiro em realizar certos comportamentos, tais como o de namoro, submissão, hierarquia nem tampouco a noção de territoriedade, ou seja, a sociedade humana não é um invento do homem.

Os cientistas conseguiram fazer o elo entre a evolução de determinadas espécies animais, mas não conseguem fazer a ligação entre nossos ancestrais primatas e o homem atual, existe aí uma lacuna de aproximadamente 10 milhões de anos. Utensílios, caça, linguagem, cultura são hábitos e costumes que podem ter aparecido antes mesmo da espécie sapiens; isso significa dizer que a sociedade humana é um processo complexo de desenvolvimento imerso na história, de onde emergiu a cultura. Acredita-se que é nessa lacuna que surge o homem, um animal humano, organizado em sociedade natural, bem como sua cultura ligada à evolução biológica (MORIN, 1973).

Nesse complexo contexto, que se inserem os autóctones, têm uma ligação estreita e íntima com a natureza, produzindo memórias socioambientais, elaboradas por meio de trabalhos e técnicas, artefatos e construções, deixando registros nas paisagens, objetos, alterações ambientais, bem como na agricultura.

Heranças resultantes de processos socioambientais e naturais portam signos construídos e relativamente autônomos, mas que conservam sintonia com o modo de pensar e agir de um povo. Sua análise gera conteúdos interpretativos úteis às sociedades atuais. Denotam maneiras dos povos se relacionarem com o ambiente, entre si e a sua construção. (LOIOLA, 2010, p. 8-9).

Dessa forma, marcadores espaço-temporais ${ }^{1}$ se transformam em memórias

\footnotetext{
${ }^{1}$ De acordo com Loiola (2011), marcadores espaçotemporais são marcas inscritas nas paisagens, na memória e interferem nas ações atuais, de modo que a compreensão da dinâmica socioambiental impõe tratar simultaneamente o presente e as heranças do passado, sobretudo as implicações dessa interação.
} 
sociais e ambientais, dando suporte às representações sociais, bem como a agricultura, promovendo as identificações étnicas e culturais. Essa afirmativa nos permite concluir que as produções dos marcadores territoriais e temporais são difundidas a partir de estreitas relações entre o momento histórico, social, ambiental e cultural, de acordo com as condições ambientais locais e de acordo com suas memórias, ou seja, são atribuídas às heranças do passado.

Para se localizar acerca do espaço e do tempo, as comunidades tradicionais se equivalem de processos histórico-sociais, de acordo com a simbologia de cada cultura, tais marcadores podem ser referenciais celestiais e ambientais. Esses marcadores, como já foi dito, resultam de um processo contínuo de aprendizagem e acúmulo de saberes, vinculados ao modo de estruturação social, com a finalidade de orientar, bem como regular os ciclos e ritmos sociais numa tentativa de perpetuar os costumes tradicionais.

\section{RESULTADOS E DISCUSSÕES}

Nas concepções de Loiola, marcadores espaço-temporais são construídos a partir de eventos tanto no tempo, quanto no ambiente e sociedade:

Desta forma, eventos inscrevem marcas no espaço-tempo socioambiental. Dos sucessivos acúmulos resultam rugosidades plenas de marcadores potencialmente manifestos, sempre à espera de novos significados, seja nos aspectos físicos, biológicos, informações, cultura material ou a memória dos povos. Se essas heranças influenciam o processo de realização geográfica é porque há uma conversão dos marcadores espaço-temporais em atributos de memórias socioambientais. (LOIOLA, 2011, p. 2).

Especificando ou focalizando a cultura Terena, nota-se que os marcadores fundamentam-se na observação da paisagem, cheias de rios, períodos de frutificação, período de caça associado à religiosidade Terena, período de chuva e estiagem e observações ligadas à astrologia. Os saberes tradicionais e saber científico estão muito próximos, embora o primeiro esteja em desvantagem nas sociedades ocidentais, uma vez que não possuem registro escrito.

A memória dos povos tradicionais não é estática, não se trata apenas de reviver o passado, mas de refazer, reconstruir, repensar, não só com ideias e imagens, mas também através de projetos, como o Yunákalu² desenvolvido na Aldeia Lagoinha, em 2013, e o Koxunákopoti Vitúkeovo $^{3}$, desenvolvido na Aldeia Ipegue, em 2014.

O projeto Koxunákopoti Vitúkeovo teve por objetivo mobilizar a escola perante a comunidade, ou seja, usar a escola como ferramenta de revitalização da cultura indígena Terena da Aldeia Ipegue, por meio das disciplinas do Ensino Fundamental. Dentro de cada conteúdo, foram abordados: Mitos Terena, Arte e Cultura, questão das moradias, medidas tradicionais correlacionando ao Sistema Internacional de Unidades e Medidas, plantas regionais e seu uso na nutrição e homeopatia, mudança de hábitos nutricionais dos Terena e a mudança na forma de aquisição dos alimentos.

Segundo Maria Alexandra, diretora da Escola Municipal Indígena Feliciano Pio, na aldeia Ipegue, o Yunákalu era praticado para arrecadar prendas para a festa. Nessa festa, havia uma disputa entre os Koixómoneti. Um ancião era escolhido entre os demais para ficar responsável pela arrecadação de prendas para a festa. Depois, fazia-se o ritual, no qual os Koixómoneti mediam forças para

\footnotetext{
${ }^{2}$ Evento realizado com a finalidade de arrecadar prendas, doações para realização da festa que homenageava os Koixómoneti (feiticeiros).

${ }^{3}$ Reafirmando nossa identidade.
} 
ver quem era o mais forte. Terminado o ritual, fazia-se um grande banquete, em que toda a população era convidada a fartar-se.

Com a chegada dos padres Redentoristas, essa festa foi adaptada para a Semana Santa. De acordo com a Maria Alexandra, o Yunákalu ainda hoje é praticado de forma adaptada, pois as prendas são doações da prefeitura municipal.

São poucas as famílias tradicionais Terena da aldeia Ipegue que ainda praticam os hábitos e costumes antigos, tais como passar o espanador nos parentes quando chegam de viagem e quando vão embora para abençoar, a reza e o ato de benzer, a utilização de remédios caseiros e a alimentação tradicional.

A família da diretora Maria Alexandra ainda pratica tais costumes, sua mãe possui uma tenda Terena dentro de casa, onde atende pessoas doentes; ela reza, benze e utiliza remédios caseiros. Dessa forma, Maria Alexandra (diretora) justifica o projeto Koxunákopoti Vitúkeovo, como uma tática de resistência desenvolvida na escola, para que os mais jovens conheçam e continuem praticando a arte e cultura de seu povo.

Os projetos desenvolvidos nas escolas são uma forma, ou tática, de reproduzir os saberes:

Essa memória não é fotográfica estática de um passado como propôs Bérgson já que na maior parte das vezes, lembrar não é reviver, mas refazer, reconstruir, repensar, com imagens e ideias de hoje, as experiências do passado. (BOSI, 1987, p. 17).

As memórias dos povos tradicionais são estimuladas por narrativas míticas, sendo individual ou coletiva, e as "ideias de hoje" se encaixam muito bem com os projetos realizados na atualidade, nas escolas indígenas. É bem verdade que isto são mecanismos de representação do espaço-temporal e também de co-reprodução do passado, como um con- junto relacional de reprodução cultural. Os marcadores espaço-temporais Terena, muitas vezes, também estão associados à representação mental da realidade geográfica, seja ela cognitiva ou performática.

Em janeiro de 1978, fazíamos uma viagem no Pantanal da Nhecolândia, era mês de janeiro, chovia muito, o pantanal estava cheio... Fomos buscar uma boiada na fazenda Cruzeiro, com destino para subir a Serra da Alegria, Rio Verde-MS. A boiada era formada por 1.100 bois. Então na fazenda havia muitos bois erados, e muitos deles precisaram ser laçados para incluí-los na boiada. No meio destes bois mais erados, havia um boi $\mathrm{osco}^{4}$, por ele ter posado amarrado no pau, machucou a paleta e ficou manco... Depois de uns cinco dias de marcha ${ }^{5}$, no ponto de almoço, ele ficou deitado e nós não vimos, logo após nós termos andando alguns quilômetros, o condutor ${ }^{6}$ e nós demos por falta do boi, aí ele pediu pra que eu voltasse, eu e um senhor chamado Lino. Aí andamos bastante a procura dele, até quase o por do sol achamos ele. Quando ele viu nós e correu, tivemos que correr atrás, laçar novamente e amarrar ele no pau novamente... Aí já se fazia noite, aí começamos a ir embora à procura da comitiva, na batida da boiada, como havia muita água e já era noite escura, o pantanal cheio de água não tem como a gente ver a bitola ${ }^{7}$, daí usamos a experiência para voltar, estávamos de burro, não víamos nada de estrada, aí eu disse pro Lino, Lino eu vou indo na frente, porque é perigoso seu burro pisar num jacaré, como ele era um se-

\footnotetext{
4 Boi avermelhado da cara preta.

${ }^{5}$ Uma marcha significa um dia de viagem.

${ }^{6}$ Chefe da comitiva.

7 Caminho que passa somente a cavalo ou carro de boi.
} 
nhor mais de idade, havia perigo do burro pular de derrubá-lo... como não dava para ver nada, eu soltei a rédea do burro pra que ele fosse à vontade, porque burro não perde, porque ele já conhecia o caminho de ida e nós já estávamos voltando... aí o Lino uma hora perguntou pra mim: Sobrinho, será que nós estamos perdidos? Eu disse pra ele: Lino, não tem como eu te falar nada, se estamos certos ou errados, estou deixando a vontade do burro. Aí quando andamos mais uns dois quilômetros, já era umas dez horas da noite, o burro olhou para o lado e deu uma orneada ${ }^{8}$, aí como a noite era muita escura, quase não dava pra ver nada, eu abaixei sobre a crina do burro e dei uma olhada para o lado esquerdo, para onde também o burro havia olhado e reconheci o capão ${ }^{9}$ onde tínhamos almoçado quando a gente ainda estava descendo só com a tropa... O burro reconheceu o lugar. Aí eu disse pro Lino: Lino, nós almoçamos ali quando nós descemos com a tropa e ele disse, será sobrinho, que é aqui mesmo? Aí eu disse pra ele, Lino, daqui uns quinhentos metros tem uma cimbra. Da cimbra no pouso, que era a fazenda Santa Zélia, dava uns três quilômetros. Como eu havia previsto, passamos pela cimbra depois de quinhentos metros. Antes de chegar no pouso, tínhamos que atravessar um coricho $^{10}$, aí mais uma vez tivemos que usar a experiência dos burros, porque havia lugares fundos à noite que a gente não percebe, só os burros, isso já era quase onze horas da noite, deixando o burro atravessar o coricho, chegamos no pouso, nos juntamos aos outros e

\footnotetext{
8 Relinchou.

9 Lugar mais alto e seco do Pantanal, utilizado pelos viajantes a cavalo, para ponto de almoço.

${ }^{10}$ Vazante do Pantanal, como se fosse um córrego.
}

seguimos viagem no dia seguinte. Subimos a Serra da Alegria, de Rio Verde à Campo Grande, Sidrolândia, Maracajú, Dourados, Naviraí, onde ficava a fazenda Jequitibá, destino da nossa viagem. Meu serviço era esse, arribador ${ }^{11}$. (Paulo Cézar Domingo, o Pancho, Aldeia Ipegue, 2014).

Na história do seu Pancho, observa-se a representação tanto mental, quanto performática do espaço geográfico, a partir do comportamento animal. Pois ele se orientava em caminhos e trilhas por meio da batida, ou rastro dos animais. Para Seeman (2003, p. 261)

\section{[...] nos seus referenciais espaço- -temporais muitas vezes a expe- riência é associada a uma repre- sentação mental da realidade por uma geografia imaginativa, seja ela cognitiva ou performática. No primeiro caso, a representação de base cognitiva ou mental inclui tanto as imagens do ambiente guardadas na mente para encon- trar caminhos ou se orientar no espaço, quanto os artefatos físicos que registram modos de perceber o espaço e os lugares.}

Outra forma de se orientar era por meio da lua ou estrelas. Os entrevistados contaram que, quando há estrelas visíveis no céu, observam que o Cruzeiro do Norte é menor. No caso da lua, observavam que ela faz o mesmo movimento que o sol, ou seja, nasce no leste e se põe no oeste. Observavam ainda, que quando "estrela grande" nasce, referindo-se à estrela Dalva (planeta Vênus), já é hora de seguir para o roçado, pois já é em torno de $4 \mathrm{~h}$ da manhã.

Os Terena têm sua forma própria de marcar o tempo, pois não relacionam o tempo com as horas, mas, sim, com o céu, tanto à noite, ao observar a lua, quanto de dia, ao observar a sombra. Segundo os

\footnotetext{
$\overline{11}$ Peão prático, que voltava para arribar ou capturar o boi perdido.
} 
Terena, a lua nova nasce de dia no sul, e à noite se vê esta ao norte como mostra $\mathrm{o}$ relato que segue:

Nos meses de fevereiro, março, abril, maio, junho e julho, a lua cheia nasce às $18 \mathrm{~h}$ e, nos demais meses, ela nasce às $17 \mathrm{~h}$. Quando a lua nasce, já é noite, nessa época escurece mais cedo. A cada hora, a lua vai mudando de posição, então contamos as horas de acordo com o movimento da lua no céu. Já o sol, a gente vê o horário pela sombra. Até dá meio dia, a sombra fica pro lado nascente, meio dia não tem sombra, depois do meio dia, a sombra fica pro lado poente. Também contamos as horas, pela posição da sombra do no chão, a cada período do dia, a sombra vai mudando de posição. (Cleuza Souza domingo, aldeia Ipegue, 2014).

Foram questionados com relação à localização, se há algum desenho que os ajude a se localizar. Disseram que, por caminhos e trilhas, faziam desenhos nas árvores, geralmente cortes horizontais para evitar se perderem no meio da floresta, quando ainda caçavam.

Com relação à caça, coleta e pesca são atividades típicas dos povos tradicionais, os Terena sabem que tipo de peixe existe em determinado local do rio, observando tanto a maré ${ }^{12}$, quanto a vegetação local. As pessoas entrevistadas disseram que lugar onde tem Tarumã tem peixe, porque quase todas as espécies de peixe comem a fruta do Tarumã.

A caça era uma das principais atividades dentre os Terena. Há algumas restrições sobre essa atividade ligadas à questão religiosa, como por exemplo, na

\footnotetext{
${ }^{12}$ Maré alta para os Terena significa rio cheio, enchente. Quando o a maré está alta, pega-se peixe de couro, como Pintado, Bagre, etc, quando a maré está baixa, pega-se peixes de escamas, como a Piranha, Pacu, dentre outros.
}

Quaresma $^{13}$, período citado como proibitivo para a prática da caça, podendo, somente, pescar. A religiosidade é bastante presente nas comunidades Terena, embora tenha assumido nova forma, como tática de resistência ${ }^{14}$, conforme afirma o etnólogo Pereira (2009), também foi caracterizada nas respostas, pois afirmam que, quando o tempo está encoberto, sem estrelas e sem lua, resta ter fé, ou seja, acreditavam que, se cressem em Deus com fé, não iriam se perder no meio do caminho

\footnotetext{
${ }^{13}$ Quaresma é a designação do período de quarenta dias que antecedem a principal celebração do cristianismo: a Páscoa, a ressurreição de Jesus Cristo, que é comemorada no domingo e praticada desde o século IV. Foi implantada na aldeia pelos Padres Redentoristas e segundo a diretora Maria Alexandra, os Terenas assimilaram o costume, todavia, adaptaram à cultura. Na madrugada da Sexta feira Santa para amanhecer o Sábado de Aleluia, os Terena da Aldeia Ipegue comemoram a Aleluia de forma bem peculiar e característica, eles fazem A Guerra das Espadas de São Jorge em forma de jogo. Os jogadores são os membros de cada bairro que formam grupos com número ilimitado de participantes. Cada grupo tem o Espadeiro, a pessoa que carrega um saco ou mais cheio de Espadas de São Jorge que serão usadas na disputa. Saem à meia noite, quando os membros dos diferentes grupos se encontram na rua, eles se surram, aquele que não aguentar, pede paz, então o outro para de bater e é considerado vencedor. O grupo perdedor vai se juntando ao grupo vencedor e combatendo os demais grupos, até restar um único grupo vencedor que saem para "roubar" galinhas e porcos. Quando amanhece, escolhem um casa para preparar o que "arrecadaram" na madrugada e então fazem um banquete e comem todos juntos.

${ }^{14}$ Para não perder seus costumes, o Terena aceita que este sofra um reajuste de acordo com o evento sociocultural e político contemporâneo, como por exemplo, a questão da religiosidade. O Cristianismo é quase que absoluto dentro das aldeias hoje, porém, caracterizado com a cultura Terena (PEREIRA, 2009). Por exemplo, nas igrejas evangélicas Terena, o pastor é Terena, os obreiros são Terena, o grupo de jovem é Terena, o círculo de oração é Terena e os hinos são Terena, como se pode comprovar nos CD's gravados pelo cantor Terena Arilson Cândido. O Terena assimila o novo, mas customiza-o a seu modo e costumes, isto é tática de resistência.
} 
e, caso se perdessem, Deus iria ajudá-los a reencontrar a direção, como afirma seu Lucídio Côrrea, da aldeia Colônia Nova.

Lembra de Deus e vai e Deus acompanha. Mas tem um mistério, às vezes perde. Não sei nem dizer como. Quando se perde não reconhece nada, a gente fica meio bobo no meio do mato, daí tem que esperar um pouco, joga uma água no rosto, parece que limpa tudo, a gente recupera os sentidos, quando melhorar vai embora. Para não perder a gente marca as árvores onde passa, mas mesmo assim às vezes perde. (Lucídio Correa, aldeia Colônia Nova, 2014).

Ainda com relação à caça, outro período em que não se pode caçar são os meses de outubro e novembro, época da parição, além dos três próximos meses (dezembro, janeiro e fevereiro) em que a matriz está amamentando como diz Lucídio Correa "[...] Porco do mato a gente caça qualquer hora. Dentro da reserva não tem nada, e o fazendeiro não deixa caçar. Cateto, anta, pode caçar o tempo todo, menos no tempo da Guavira, porque estão prenhes, igual ao peixe" (Lucídio Côrrea, aldeia Ipegue, 2014).

Para caçar, os Terena utilizam cachorro, zagaia e armadilhas, como apontado pelo seu Celsinho:

[...] caçamos no mato, com companheiros e cachorros. Os animais do mato são muito bravos. Temos que ficar muito atentos quando encontramos animais em bandos, principalmente o queixada, porco de colera branca, eles atacam e cortam tanto cachorro quanto a gente, ele têm dentes afiados. (Celsinho Luiz Mendes, 'Simí', aldeia Ipegue, 2014).

Os entrevistados explicaram que também faziam um forje ${ }^{15}$ bem tapado,

\footnotetext{
${ }^{15}$ Espécie de buraco na trilha dos animais, sendo a
}

na trilha dos animais, com a boca bem estreita e solapeia por dentro.

Não existe época específica para cada caça, geralmente caça-se o ano inteiro, com exceção dos meses de outubro e novembro porque, nesse período, as fêmeas estão prenhes e já começam a parir. Na grande maioria das espécies existentes na região dos Terena, a época de acasalamento, reprodução e parição, geralmente é a mesma. Seu Paulo Cezar, o Pancho, conta que a melhor época para caçar a paca é, geralmente, dois ou três dias após a lua cheia, porque pacas gostam de noites escuras. Ainda sobre restrições, disse que não pode caçar o tatu peludo, o Peba, no mês de agosto (período de plantio da rama da mandioca), pois ele se encontra "empesteado", assim como o lagarto, devido ao fato de ainda não haver mandioca para comer.

O período de longa estiagem faz com que muitos animais morram doentes por falta de água e alimento, então o tatu e o lagarto alimentam-se dos restos em putrefação desses animais que morreram em função da seca e doenças, por isso diz-se que nessa época estão "empesteados".

Além da caça e da coleta de frutos, há também o período do plantio, quando as atividades são guiadas ou regidas pelos marcadores espaço-temporais Terena. Os Terena são excelentes agricultores, atividade observada por viajantes que se aventuram em terras brasileiras por meados do século XVI, tais como Hercule Florence, Francis Castelnau e Schimdel, citados do primeiro capítulo.

Nas perspectivas de Ramos (1988,

Quase todas as sociedades indígenas da América do Sul praticam a agricultura, umas de forma mais elaborada, outras de maneira mais rudimentar. Ela pode ser a atividade econômica principal ou apenas complementar um sistema

abertura estreita e por dentro com maior diâmetro. 
produtivo mais dependente da caça, pesca ou coleta.

Os Terena marcam o início e o fim do ano pelo plantio e pela colheita, assim como a primavera, outono, verão e inverno, de acordo com o quadro abaixo:

\begin{tabular}{l|l}
\hline Verão & $\begin{array}{l}\text { Época de plantar e colher o arroz, colher } \\
\text { guavira, melancia e manga. }\end{array}$ \\
\hline $\begin{array}{l}\text { Outono, também conhecido como tempo } \\
\text { das folhas secas. }\end{array}$ & $\begin{array}{l}\text { Época de plantar o feijão, tanto o convencional } \\
\text { quanto o miúdo, sendo este um pouco depois, } \\
\text { e colher o milho. }\end{array}$ \\
\hline Inverno & $\begin{array}{l}\text { Época de colher o feijão, mandioca e cana-de- } \\
\text { açúcar. }\end{array}$ \\
\hline $\begin{array}{l}\text { Primavera, também conhecida como } \\
\text { "florada". }\end{array}$ & Plantio da abóbora e melancia. \\
\hline
\end{tabular}

Quadro 1 - estações do ano relacionadas à época de plantio Terena da Terra Indígena Taunay-Ipegue, município de Aquidauana, MS.

Fonte: Dados colhidos a campo mediante observações empíricas de membros da comunidade.

A lua é observada na orientação do plantio de cada espécie, segundo seu Pancho (2014), cada período da lua é de sete dias e geralmente há mudança de tempo na lua nova. Diz ainda que se a lua nova está pênsil ${ }^{16}$, sinal de chuva e que, geralmente chove na lua nova ou na quarta crescente. Geralmente não se planta nada na nova, pois caruncha ${ }^{17}$.

A lua nova traz chuva. Não se colhe nada na nova, nem corta madeira, porque caruncha. Se colher milho na nova, ele vai carunchar, qualquer tipo de grão que se colhe na nova, em geral caruncha mais rápido do que o habitual. (Paulo Cézar Domingo, 'Pancho', 58 anos, aldeia Ipegue, 2014).

Embora o preparo do solo hoje seja feito por meio de máquinas, que gradeiam a terra, ainda assim, os Terena observam a natureza para iniciar o período de plantio,

\footnotetext{
${ }^{16}$ Levemente inclinada para a direita, como se fosse uma bacia cheia d'água na eminência de transbordar.

17 Verbo oriundo do substantivo caruncho. Caruncho: inseto da ordem dos coleópteros que perfuram madeiras, cereais etc. Brocas que atacam espécies vegetais vivas.
}

como florada das plantas, as chuvas, os períodos de estiagem e os ventos, e medem o seu roçado utilizando as medidas tradicionais, tais como a braça ${ }^{18}$, a tarefa de enxada ${ }^{19}$ e a tarefa de foice ${ }^{20}$. Muitos ainda utilizam-se do trabalho coletivo para cultivar sua roça, sendo uma relação de troca, ou seja, todos ajudam a plantar a área de determinado morador, depois vão alternando entre os envolvidos na tarefa, até plantarem as terras de todos. Outros contratam o trabalho local, que chamam de changa ${ }^{21}$. Segundo seu Pancho, milho e arroz se trabalham na tarefa de foice, feijão miúdo, melancia, abóbora, na tarefa de enxada.

Para medir um hectare de terra, utilizam-se também de outra medida

\footnotetext{
${ }^{18}$ Uma braça significa dois metros, e os Terena utilizam-se dos braços abertos, sendo considerado de uma ponta dos dedos à outra, para fazer esta medida.

${ }^{19}$ Uma tarefa de enxada mede doze braças e significa um quarto de hectare.

${ }^{20}$ A tarefa de foice mede vinte e cinco braças e significa meia hectare de terra.

${ }^{21}$ Trabalho temporário, que geralmente dura o tempo de concluir três ou quatro tarefas, alternando o tempo de acordo com o tipo de tarefa, que pode ser de foice ou de enxada.
} 
tradicional, as $\operatorname{covas}^{22}$ de mandioca, que fazem nas cabeceiras ${ }^{23}$, sendo cem covas de mandioca, com a distância de um metro uma da outra e um metro quadrado de diâmetro o seu tamanho.

O quadro a seguir, de acordo com as estações do ano, mostra o calendário agrícola da aldeia Ipegue, município de Aquidauana, MS. É importante frisar que a prática da agricultura na aldeia Ipegue está bastante escassa, desmotivada pela falta dos implementos agrícolas, introduzidos na aldeia por meio da FUNAI por volta da década de 60 e 70 . O trabalho não é coletivo e, geralmente, está associado à outra prática rentável e geralmente obedece à agricultura de subsistência, vendendo-se localmente o que não se consome.

De acordo com os dados colhidos em campo, todo plantio, ou seja, toda espécie plantada, com exceção do feijão, que se colhe com aproximadamente sessenta dias, as demais espécies se colhem, geralmente, com as condições climáticas favoráveis, em 120 dias.

\begin{tabular}{l|l|l|l|l|l|l|l|l|l|l|l|l}
\hline & Jan & Fev & Mar & Abr & Maio & Jun & Jul & Ago & Set & Out & Nov & Dez \\
\hline Preparo do solo & & & & & & & & & & & & \\
\hline Plantio de rama & & & & & & & & & & & \\
\hline Colheita de mandioca & & & & & & & & & & & & \\
\hline Plantio de feijão convencional & & & & & & & & & & & & \\
\hline Colheita do feijão convencional & & & & & & & & & & & & \\
\hline Plantio do feijão miúdo & & & & & & & & & & & & \\
\hline Colheita do feijão miúdo & & & & & & & & & & & & \\
\hline Plantio de milho & & & & & & & & & & & & \\
\hline Colheita do milho & & & & & & & & & & & & \\
\hline Plantio de arroz & & & & & & & & & & & & \\
\hline Colheita do arroz & & & & & & & & & & & & \\
\hline Plantio de cana-de-açúcar & & & & & & & & & & & & \\
\hline Colheita da cana-de-açúcar & & & & & & & & & & & & \\
\hline Plantio de abóbora & & & & & & & & & & & \\
\hline Plantio de melancia & & & & & & & & & & & \\
\hline Colheita da melancia & & & & & & & & & & & \\
\hline Coleta de Guavira & & & & & & & & & & & & \\
\hline
\end{tabular}

Quadro 2 - Calendário agrícola Terena

Fonte: Quadro adaptado da tese de dissertação de Claudionor do Carmo Miranda, Campo Grande, MS, 2006. Dados de campo obtidos pela autora por meio das observações empíricas e entrevista direta com os agricultores da aldeia Ipegue e Colônia Nova, município de Aquidauana, MS.

Ainda na florada, como costumam dizer, já é possível saber se a produção de manga, laranja, milho e arroz vai ser boa, bastante flor, sinal de muito fruto. Sob as perspectivas dos Terena agricultores,

\footnotetext{
${ }^{22}$ Abertura no solo, também chamada de berço, pelos agricultores Terena mais novos.

${ }^{23}$ Refere-se, às duas extremidades mais estreitas do roçado, sendo as duas mais compridas chamadas de laterais.
}

chuva boa é a chuva de verão, o Veranio ${ }^{24}$, como costumam dizer é ruim, é o que traz as chuvas de inverno.

Observam o período de estiagem por meio do solo, pois afirmam que, quando não dá para andar descalço durante $o$ verão, pode-se preparar para um período

\footnotetext{
${ }^{24}$ Período de seca no mês de novembro, verão sem chuva.
} 
de longa estiagem. Quando a paquinha ${ }^{25}$ (Família Gryllotalpidae) aparece, é sinal de chuva, pode contar daí no máximo, no período de três a quatro dias, que irá chover. Os Terena associam a aparição de animais peçonhentos com chuva, como, por exemplo, aranha caranguejeira (família: Theraphosidae), formiga de correição (subfamília Ecitoninae). Para eles, quando esses bichos aparecem, é sinal de chuva, bem como quando o jacaré (Família Alligatoridae) bufa e as rãs (família Ranidae) cantam.

Vento norte no mês de Agosto só serve para secar a terra. Vento sul é frio e úmido. Geralmente depois de três ou quatro dias de vento norte forte, tem chuva, porque o vento norte vai pro sul e volta trazendo chuva. Vento leste significa muita seca e não tem chuva e o vento oeste trás muita chuva, chuva com fortes ventos, tempestade. (Paulo Cézar Domingo, 'Pancho', aldeia Ipegue, 2014).

Percebe-se, por meio desses relatos, que os anciãos ainda guardam, mantêm vivos muitos conhecimentos e tradições, embora o povo Terena seja conhecido como "índio urbano", de acordo com as reflexões de Roberto Cardoso de Oliveira em sua obra "O Processo de Assimilação dos Terena”, 1960. O Terena é um povo itinerante, mas que sempre volta para sua aldeia de origem. Nas perspectivas de Pereira (2009), o Terena observa o mundo ocidental, os costumes, hábitos, cultura e traz isso para dentro da aldeia, para si, mas, com "cara" Terena, com "roupagem" Terena. A agricultura Terena vem resistindo aos impactos causados pelo contato com o mundo ocidental, o que é imprescindível. Ainda de acordo com Pereira (2009), este seria um artifício, uma tática de resistência.

Dessa forma, a cultura Terena tem sobrevivido ao tempo, às lutas, às mazelas do Governo, do mundo ocidental e

${ }^{25}$ Inseto. esses são os signos de uma cultura secular viva, dinâmica e permeável, cujo percurso descreve os seus marcadores espaço-temporais, signos de suas memórias sociais e ambientais.

\section{CONSIDERAÇÕES FINAIS}

Podemos concluir que os marcadores temporais estão presentes na cultura Terena sob a forma de representações cognitivas, mapas mentais, memórias cronológicas, por meio de ritos ou mitologia. Todas essas ações são determinadas pela herança histórica e cultural Terena, todos esses signos carregados de significados, crença, religiosidade, são convertidos em marcadores espaço-temporais, que, posteriormente, serão transformados em memórias socioambientais.

A tradição oral, rituais, saberes, a relação íntima com a natureza têm sido deixados de lado com o passar do tempo e a morte dos anciãos; $\mathrm{e}$, nestas perspectivas de reafirmação da identidade e verbalização desses conhecimentos, é que este trabalho foi realizado.

Costumes tradicionais e heranças do passado costumam deixar suas marcas na paisagem, nas memórias e nas informações socioculturais de um povo, que são dimensionadas no espaço e no tempo socioambiental. Observar os resíduos do passado na realização de atividades cotidianas requer um olhar onipotente, que vai além das estruturas, formas e ações do presente. Para tanto, foi necessário, além de observar os costumes herdados, buscar nesses significados a explicação das memórias socioambientais, fazer um resgate do conhecimento empírico. Signos do passado e presente se entrelaçam e são direcionados socioculturalmente, partindo de regularidades celestiais, como o Cruzeiro do Sul, Caminho da Ema, Estrela Dalva ou Estrela Grande, ciclos ambientais, como a estação das chuvas e da seca, que são reguladores do plantio, da colheita, da coleta e da caça. 
Todos esses aspectos, somados ao ritmo social, são convertidos em marcadores espaço-temporais. Todo esse processo é o resultado do acúmulo de aprendizagem de diferentes saberes, a relação socioambiental está para o Terena, assim como o Terena está relacionado com o ambiente, numa relação insolúvel de espaço-temporal, dinâmico e fecundo da natureza (LOIOLA, 2011).

Esse levantamento sobre os marcadores espaço-temporais são expressões dos saberes tradicionais impossíveis de serem aprendidos fora desse ambiente sociocultural. Há milhares de anos se têm notícias sobre o uso dos marcadores espaço-temporais pelas mais diversificadas e distintas sociedades, ora por meio dos movimentos celestiais, ora por meio dos fenômenos climáticos, ciclos naturais, biológicos ou por meio de fenômenos socioculturais. Contudo o uso desses marcadores não é unanimidade, suas escolhas seguem padrões culturais e demandas peculiares de cada povo, associado também à demanda ambiental, assumindo, dessa maneira, formas diferentes em cada região, como por exemplo, o Caminho de Santiago para os nordestinos, é o Caminho da Ema para os Terena. Há que se dizer que esses marcadores ainda são usados por uma pequena parcela da comunidade, associados à modernidade e à tecnologia. O Terena acompanha a evolução, se beneficia das tecnologias disponíveis, porém ele transforma ou converte isso tudo a seu modo, dá uma característica peculiar.

O Terena não fica parado no tempo, ele evolui, acompanha a modernidade, mas traz consigo os saberes, os costumes tradicionais, ajustados a esta modernidade, como é o caso da lida com a terra, usa a tecnologia disponível, mas se orientando pelos costumes tradicionais, conforme sua crença.

O discurso ocidental associa as profissões ligadas à terra como penosas e sofridas, em função desse discurso controvertido é que a maioria dos jovens Terena têm deixado de acompanhar seus pais para o trabalho nas "roças" ${ }^{26}$. Em função disso, o trabalho realizado foi de extrema relevância, pois esse levantamento e registro pode ser utilizado nas escolas como forma de valorizar a cultura na tentativa de mudar o olhar dos mais jovens, para que estes tenham orgulho da sua cultura própria e única.

Fique registrado o profundo apreço pela cultura Terena ${ }^{27}$, hábitos e costumes, assim como o agradecimento às comunidades de Ipegue e Colônia Nova pela contribuição nas entrevistas concedidas, pois este é apenas um primeiro degrau, dentre os quais, ainda pretendemos subir em relação à educação e profissão.

\section{REFERÊNCIAS}

BITTENCOURT, Circe Maria; LADEIRA, Maria Elisa. A história do povo Terena. Brasília: MEC, 2000.

BOSI, Ecléa. Memória e sociedade: lembrança de velhos. 2. ed. São Paulo: EDUSP, 1987.

LOIOLA, Sérgio Almeida. Do espaço e tempo ao espaço-tempo: dimensões e marcas. Geografia, Associação de Geografia Teorética AGETEO, Rio Claro, v. 35, n. 1, p. 5-20, jan,/ abr. 2010.

LOIOLA, Sérgio Almeida; OLIVEIRA, Sandra de Fátima; RATTS, Alecsandro J. P. Objetos, ações e processos naturais: de marcadores espaço-temporais às memórias socioambientais. Revista do Departamento de Geografia - USP, São Paulo, v. 21, 2011.

MARIA, E. C. Entrelaçando conhecimentos e saberes: educação ambiental na escola indígena Marcolino Lili - Aquidauana-MS, 2011. Dissertação (Mestrado em Ensino de Ciências) - Universidade Federal do Mato Grosso do Sul, Campo Grande, MS, 2011.

\footnotetext{
${ }^{26}$ Porção de terra cultivada com grãos, árvores frutíferas, abóbora, melancia, batata, dentre outros.

${ }^{27}$ Apreço por minha história, pois faz parte do que eu sou enquanto índia Terena.
} 
MIRANDA, C. C. Territoriedade e práticas agrícolas: premissas para o desenvolvimento local em comunidades Terena de MS. 2006. Dissertação (Mestrado em Desenvolvimento Local) - Universidade Católica Dom Bosco, Campo Grande, MS, 2006.

MORIN, Edgar. O paradigma perdido: a natureza humana. 5. ed. Portugal: Publicações Europa-américa, 1973. Disponível em: <http:/ / ruipaz.pro.br/textos/ paradigma. pdf>. Acesso em: 10 out. 2014.

OLIVEIRA, Roberto Cardoso de. O processo de assimilação dos Terêna. Rio de Janeiro: Museu Nacional do Rio de Janeiro, 1960.

PEREIRA, Levi Marques. Os terena de Buriti: formas organizacionais, territorialização e representação da identidade étnica. Dourados: Editora UFGD, 2009.

RAMOS, Alcida Rita. Sociedades indígenas. 2. ed. São Paulo: Editora Ática, 1988.
SEEMANN, Jörn. Mapeando culturas e espaços: uma revisão para a geografia cultural no Brasil. In: ALMEIDA, Maria G; RATTS, Alecsandro José Prudêncio (Org.). Geografia: leituras culturais. Goiânia: Alternativa, 2003. p. 261-284.

TASSINARI, Antonella M. I. Sociedades indígenas: introdução ao tema da diversidade cultural. In: SILVA, Aracy Lopes; GRUPIONI, Luís Donisete Benzi (Org.). A temática indígena na escola: novos subsídios para professores de $1^{\circ}$ e $2^{\circ}$ graus. Brasília: MEC/MARI/ UNESCO, 1995.

THOMAZ, Omar Ribeiro. A antropologia e o mundo contemporâneo: cultura e diversidade. In: SILVA, Aracy Lopes; GRUPIONI, Luís Donisete Benzi (Org.). A temática indígena na escola: novos subsídios para professores de $1^{\circ}$ e $2^{\circ}$ graus. Brasília: MEC/MARI/UNESCO, 1995.

\section{Sobre as autoras:}

Sandra Ventura Domingo: Professora da educação básica pela rede municipal de educação em Aquidauana. Graduanda em Ciências da Natureza pelo Curso de Licenciatura Intercultural Indígena "Povos do Pantanal". E-mail: ventura_terena@hotmail.com

Elisangela Castedo Maria: Universidade Federal do Mato Grosso do Sul. Graduada em Ciências com Hab. em biologia especialista em maneja de recursos naturais especialista em Gestão Escolar Mestre em Ensino de Ciências Professora do curso de Licenciatura Indígena Povos do Pantanal - UFMS. E-mail: ecmcursino@yahoo.com.br 
